\title{
SOCIABILIDADE E ENVELHECIMENTO FEMININO NOS BAILES DE DANÇA DE SALÃO EM FORTALEZA.
}

\author{
Monalisa Dias de Siqueira ${ }^{1}$
}

Uma das questões principais para a compreensão dos processos de envelhecimento e a experiência corporal nessa fase da vida são as formas de sociabilidade que surgiram nas últimas décadas. Em Fortaleza, capital do estado Ceará, a exemplo de outras cidades brasileiras, é possível observar um considerável número de espaços e atividades para a "terceira idade" como Universidades para terceira idade, atividades esportivas nas praças e academias, cursos e palestras, excursões, grupos de oração, grupos de convivência, bazares e os bailes de dança de salão.

Nesses bailes, os vínculos sociais são buscados e experimentados por mulheres e homens de diferentes faixas etárias e camadas sociais ${ }^{2}$. Desse modo, existem interesses e motivações (Simmel, 2006) que levam mulheres mais velhas a buscarem os bailes de dança de salão como forma de sociabilidade. Como também, existem sentidos e significados relacionados à escolha da dança de salão, à sua ligação com os desejos e as emoções experimentados desde a opção de sair de casa para dançar até o encontro com o parceiro de dança no baile, onde estão presentes os olhares, as músicas e o enlaçamento dos corpos na dança a dois.

Em Fortaleza existe um “circuito” (Magnani, 1998) da dança de salão no qual clubes, casas de shows e restaurantes estão dispostos em diferentes bairros da cidade, tanto aqueles considerados de "periferia" quanto "nobres". Tais estabelecimentos funcionam de terça a domingo e contam com um público assíduo que ocupa os salões para dançar bolero, samba de gafieira, forró, soltinho e tudo o mais que os músicos tocarem.

Homens e mulheres, pagando ingresso ou o couvert artístico, ocupam as mesas independentemente do dia da semana. A maioria são mulheres que exibindo suas saias ou vestidos rodados, sandálias de salto alto, maquiagem e adereços, chegam para dançar. Há também casais, alguns homens desacompanhados e, sobretudo, dançarinos profissionais disponíveis para “dançar de ficha” ou “contrato” com mulheres denominadas de "clientes” ou "contratantes".

\footnotetext{
1 Universidade Federal do Ceará, Ceará.

2 Os dados apresentados ao longo do texto são referentes à pesquisa de campo desenvolvida para a elaboração da dissertação de mestrado em sociologia (Siqueira, 2009).
} 
Muitas mulheres optam pelo pagamento de dançarinos para, principalmente, ter a certeza de dançar durante a festa, tendo em vista que os homens não-dançarinos são poucos e, dentre eles, alguns estão acompanhados, outros não dançam e há aqueles que convidam apenas as mulheres que conhecem ou que já viram alguma vez nos bailes. $\mathrm{Na}$ maioria dos casos, quando estes cavalheiros convidam as damas, eles estão consumindo bebidas alcoólicas e dançam poucas músicas, ações que geram insatisfação e queixas entre as freqüentadoras dos bailes.

Assim, as clientes têm duas opções de pagamento para dançar com os dançarinos. Uma delas é “dançar de ficha”, ou seja, comprar fichas e repassá-la a um ou mais dançarinos. Cada ficha custa $\mathrm{R} \$ 1,00$ (um real) e equivale a uma música. Desse modo, ela compra uma quantidade de fichas e escolhe o(s) dançarino(s) e as músicas de sua preferência. A mulher pode estabelecer quantas músicas quer dançar antes de iniciar os primeiros passos no salão, ou ainda, começar a dançar e ao final de algumas músicas repassar as fichas (ou dinheiro) correspondentes. Em seguida, ela se dirige de volta à mesa, até o momento da próxima dança, onde novamente escolherá o dançarino e reiniciará a negociação. O dançarino, por sua vez, fica próximo ao salão à espera da próxima cliente.

A outra opção é o pagamento do “contrato”. Este se firma, geralmente, antes da festa, onde a cliente faz um contato por telefone, na academia de dança ou numa festa anterior. A maioria das clientes e dos dançarinos se conhece, pelo menos de vista, em algum desses espaços. É recorrente a troca dos números de telefones para, posteriormente, marcarem o dia, o horário e o local do próximo baile.

Muitas vezes, com a freqüência dos contratos e a relação amigável entre ambos, os dançarinos também ligam para informar os dias livres na semana e “convidálas” para o baile. No entanto, existem algumas clientes que optam por "fechar o contrato” apenas ao chegar à festa e tomar ciência dos dançarinos que estão disponíveis, mas, também nesses casos, há algum conhecimento prévio entre eles.

Ao final da festa, a cliente pagará o serviço do dançarino, assim como a consumação de sua mesa. É comum que duas ou mais clientes dividam o contrato com o mesmo dançarino na festa e conseqüentemente, os ingressos e o consumo de comidas e bebidas do grupo. Como ouvi de um dos dançarinos: "Faz parte da cultura da dança que a cliente pague o contrato, a entrada ou o couvert, a comida e a bebida, menos bebida alcoólica” (R., dançarino, 26 anos). Em outras palavras, quando a cliente escolhe “dançar de contrato” ela terá a companhia do dançarino durante toda a festa. Isso 
implica que ele irá dançar com a cliente, sentar na sua mesa, conversar, comer e beber (consomem-se, em geral, petiscos, água, refrigerante e suco). Porém, alguns dançarinos se recusam a estabelecer um contrato no qual tenham que dançar com mais de uma cliente por baile.

O preço do contrato é, em média, R\$ 70,00 (setenta reais), podendo variar de acordo com alguma situação específica. De acordo com as informações dos dançarinos, os valores podem variar de $\mathrm{R} \$ 50,00$ a $\mathrm{R} \$$ 150,00. A diferenciação de preço depende de alguns fatores como, por exemplo, a freqüência com a qual a cliente contrata o mesmo dançarino. Desse modo, eles podem ajustar um valor abaixo da média, mas que em virtude da quantidade de bailes semanais é vantajoso para ambos, pois ela tem a certeza de um parceiro de dança "fixo" e ele de uma "cliente fixa”.

Outro caso de valores de “contrato” diferenciados é quando a cliente contrata o mesmo dançarino para dois bailes na mesma noite, então é possível que eles acordem um valor um pouco menor para um dos bailes. Existe, ainda, a distinção entre “dançarinos mais antigos” (com maior grau de profissionalização ou investimento pessoal) e os “iniciantes”, esse também é um possível critério para cobrar valores acima ou abaixo da média.

Um dos locais mais freqüentados pelas clientes e dançarinos é o Restaurante Alpendre da Villa ${ }^{3}$, onde as terças-feiras, as quartas e domingos acontecem bailes dançantes. Segundo os freqüentadores o “melhor dia é a terça com o Fonseca Jr.”, um dos grupos musicais que atrai muitas clientes e dançarinos aos bailes da cidade. Nos dias de terça-feira às 20h a movimentação já é intensa na Rua Armando Monteiro, no bairro Vila União. Por isso, quem pretende ocupar as mesas da área dançante (onde estão localizados o palco e o salão) precisa chegar antes do início da festa que começa pontualmente às $20 \mathrm{~h} 30 \mathrm{~min}$.

Um amplo estacionamento abriga os carros que trazem as freqüentadoras das festas. Algumas vão de táxi e descem em frente ao restaurante ${ }^{4}$. São, em geral, mulheres a partir dos 50 anos que chegam em dupla ou grupo de amigas e/ou acompanhadas com os dançarinos contratados. Os dançarinos, com idade entre 18 e 30

\footnotetext{
${ }^{3} \mathrm{O}$ restaurante Alpendre da Villa funciona diariamente, a partir do horário de almoço, e a cada noite apresenta uma programação musical diferente. Conta com um espaço dançante e não-dançante, um espaço infantil e um campo de futebol society. Nos dias de baile é freqüentado também por mulheres acompanhadas de seus namorados, maridos e familiares. Porém, trato aqui daquelas que freqüentam o restaurante para dançar com dançarinos profissionais.

${ }^{4}$ Nos meses em que transcorreu a pesquisa não vi mulheres chegando a pé ou de ônibus em qualquer um dos bailes.
} 
anos, chegam ao restaurante de ônibus, moto (própria ou moto-táxi), de carona com alguma cliente ou colega de profissão.

Quando uma mulher vai ao baile em companhia somente do dançarino e marcam o encontro já no local do baile, é comum que ele a espere do lado de fora do estabelecimento para que possam entrar juntos. Os casais entram de mãos dadas ou braços entrelaçados. Os grupos de amigas entram lado a lado ou bem próximas umas das outras. Os homens que irão "dançar de ficha”, ou seja, que não marcaram previamente com alguma cliente, entram sozinhos. Porém, é bastante raro ver uma mulher adentrar a porta do restaurante, da casa de show ou do clube sozinha.

Ao entrarem no restaurante, casais e grupos de amigos procuram acomodarse nas mesas. A decoração do espaço e a luz das velas dão um toque aconchegante e agradável ao local. As mesas que circundam o salão são as primeiras a serem ocupadas. Uma música ambiente antecede os músicos que nesse instante preparam seus instrumentos e organizam os últimos detalhes para dar início ao show. Os garçons circulam de um lado para o outro e os pedidos começam a surgir: refrigerantes, coloridas jarras de suco de fruta, água, petiscos tipo batata frita e pastéis. Alguns optam por jantar e apressam seus pedidos antes da banda começar a tocar.

Esse também é o momento em que os dançarinos e clientes se encontram, se cumprimentam e conversam um pouco. Muitos olhares de homens e mulheres em todas as direções: para uma pessoa conhecida que chega; para um casal a procura de mesa; para ver quais os dançarinos “estão de ficha”; quem está “de contrato”. Nos banheiros femininos as mulheres retocam o batom, arrumam os cabelos, conversam sobre a festa, a dança, os dançarinos, a família. Nos banheiros masculinos, um dos pontos de encontro mais freqüentes dos dançarinos, eles tecem comentários sobre as clientes, os últimos passos de dança, as aulas ${ }^{5}$.

Finalmente, chega a hora de iniciar o show. Às 20h30min o primeiro bolero da noite começa a ser cantado. Casais de braços entrelaçados pisam pela primeira vez o salão ${ }^{6}$ e ao som das românticas músicas os movimentos de pernas, braços, cabeça, tronco vão fluindo, assim como as conversas ao pé do ouvido, os sorrisos e os olhares.

\footnotetext{
${ }^{5}$ Evidentemente, não tive acesso ao banheiro masculino em nenhum dos bailes, mas, como sempre estava em companhia de algum dançarino, "dançando de contrato" ou "de ficha”, e nas conversas informais que tecíamos nas mesas e nos intervalos da festa perguntava sobre os comentários mais recorrentes neste ambiente. O banheiro é o lugar de privacidade dos dançarinos nos bailes. Ao reunirem-se no banheiro, longe dos olhares e ouvidos das clientes, estes não somente tratam da higiene pessoal, como também, ficam a vontade para discutirem quaisquer assuntos entre si.

${ }^{6}$ Observei que ninguém atravessa ou caminha pelo salão de dança antes ou durante o baile.
} 
Rapidamente o salão fica cheio e entre o “dois pra lá, dois pra cá”, o “leque”, o “oito” e outros tantos rodopios e figuras características do bolero, uma série de sensações vão surgido no corpo e na mente dos dançantes.

Nas conversas são comuns os comentários sobre o corpo dançarino, como esses de duas contratantes que apresento, respectivamente:

[...] a música que você escuta é que dá a sensibilidade. Pra gente que ta dançando é uma coisa prazerosíssima, sua sensibilidade mais a técnica é que faz você desenvolver as figuras e os passos bonitos [...] na dança aflora coisas que eu nem sei mais repetir [...] dançar é muito bom, tira o stress, na hora que eu danço vou acionar meu cérebro para a musicalidade, a sensibilidade e a relação como o parceiro que é o que fica bonito para o povo ver. (C., advogada, administradora e auditora fiscal federal aposentada, 61 anos).

[...] quando eu comecei a me envolver com a dança de salão, Ave Maria! Pra mim foi assim tudo, foi muito bom, foi muito bom mesmo, foi prazeroso, foi estimulante, foi assim como se, de repente, tivessem me tocado com uma varinha mágica e dissessem assim: vai, faz que isso vai te fazer muito bem... E aí eu fui aperfeiçoar nas próprias festas. (F., jornalista, 50 anos).

Os corpos entram em contato uns com os outros, há um desejo de sentir sensações que a música, a dança e o encontro com o outro proporcionam. As idéias e sentimentos dos indivíduos são expressos pelo fluir de seus movimentos e se tornam visíveis nos gestos de cada passo de dança.

Com base nas observações de campo e o diálogo com os freqüentadores dos bailes, percebo que passar por aquelas portas que dão acesso ao baile tem diferentes significados para homens e mulheres (Van Gennep, 1977) ${ }^{7}$. Ambos estão em fases distintas da vida, cada um com suas trajetórias e expectativas.

As mulheres, na maioria viúvas ou separadas, ao atravessarem a porta do restaurante encontrarão lazer, amizades, o prazer da dança, um “exercício para o corpo e para a mente”, um momento para esquecer as tarefas diárias, da casa e do trabalho, dos filhos e netos, para exercer um encontro consigo mesma e com o outro. Como observamos na fala de uma das entrevistadas:

\footnotetext{
${ }^{7}$ Van Gennep é o primeiro autor a preocupar-se com os rituais como objeto de estudo. Ele observa uma série de manifestações sociais e sistematiza o estudo de ritos como: ritos de porta e soleira, da hospitalidade, da adoção, da gravidez, do parto, do nascimento, da infância, da puberdade, da iniciação, da ordenação, da coroação, do noivado, do casamento, dos funerais e das estações. Com isso, analisa questões do indivíduo com relação ao seu ciclo biológico vital, ao ciclo familiar, à passagem do tempo etc, mostrando, assim, a ligação entre rito e estrutura social. O autor aponta para um cenário "dramático" (teatral) dos rituais, que possibilita o desencadeamento de emoções coletivas. Entre os diversos ritos que o autor analisa em sua obra, aqueles referentes à passagem material são interessantes para refletir sobre o significado da passagem dessas mulheres e homens na porta do restaurante.
} 
(...) a dança de salão é uma coisa que preenche, preenche uma lacuna, porque ela faz com que a pessoa faça amizade, renove as amizades existentes, faz com que a pessoa trabalhe o corpo, trabalhe a alma, o espírito, né? Ela é uma terapia, porque a partir do momento que você opta pela dança, é quase como se ela fosse um vício, você já ta pensando: como é que eu vou dançar hoje? Qual é a roupa que eu vou? Eu quero um sapato confortável pra não cansar muito [...] E aquilo ali é um conjunto de vantagens que só vem a somar na vida da pessoa, principalmente na vida da mulher, né? (F., jornalista, 50 anos).

Elas se afastam de certo grupo e das atividades cotidianas e a partir do instante em que cruzam a porta o coletivo ao qual se integrarão no baile possibilitará reavivar uma série de símbolos que construirão uma outra realidade.

Observando a socialização dessas mulheres e o contexto social no qual estão inseridas, é possível pensar em algumas explicações para que no momento da passagem busquem a mão ou o braço de um homem. Não é agradável para elas chegarem desacompanhadas ao baile. Como também não o é sentar-se sozinha à mesa. O prazer, a alegria e o entusiasmo de estar nesses locais estão diretamente referidos ao encontro com o outro, seja a companhia das amigas ou do dançarino.

Nunca vou só, tem que ir com alguém pra ficar conversando, né? Já que eu não sou de beber, tem que ir pelo menos com uma amiga pra bater papo, se divertir, conversar, botar o assunto em dia, ver pessoas novas, conhecer pessoas, até pelo ambiente também que é bom, é um lazer, eu vou pelo lazer. E conhecer pessoas, pessoas diferentes [...] O que eu mais gosto é da dança em si; vou mais com o intuito de dançar, quando não tem dança é bom também, mas é mais satisfatório quando se tem dança. (E., pensionista, 55 anos).

A busca de vínculos sociais e a opção de pagar o serviço de um dançarino são atitudes vistas positivamente:

(...) cria um vínculo de amizade [com o dançarino], você não fica presa a companhias: você só vai a uma festa de a fulana for. Porque só você não quer ir, porque é chato chegar na festa sozinha, sentar sozinha, fica meio ruim, né? Então você fica presa a esse tipo de coisa, se a amiga não for você não vai. E ai num contrato desse você não espera por ninguém. Dez horas o cabra tá te pegando na tua casa, vai pra festa, termina a festa ele te deixa na tua casa e vai embora e pronto. Solucionado, não é? E isso é bom, é muito bom. A família confia, sabe que a gente ta bem entregue, pelo menos comigo! Não fica aquela frescura: mamãe onde é que a senhora está? Com quem a senhora está? Até porque a primeira coisa que faço quando mudo de dançarino é levar em casa, apresentar a família toda, até os cachorros sabem quem é. Apenas pra tranqüilizar, saber quem é a pessoa, porque também eu não sou muito de ta justificando não, sabe? Essa história de: mamãe quanto a senhora gasta por festa? Quanto a senhora paga pra fulano, não tem essa pergunta porque eu não permito isso. Eu acho Monalisa que eu trabalhei a vida toda, ralei a vida toda, tudo comigo foi com muita responsabilidade e no final da história ou no auge da situação eu vou ta justificando? Não, justifico não! (R., advogada e funcionária pública aposentada, 61 anos).

Sua fala expressa a responsabilidade consigo mesma, a busca de liberdade e autonomia. A valorização da independência, a capacidade de cuidar de si e o 
reconhecimento por parte de outros indivíduos, como os parentes e amigos, são pontos importantes para demarcar uma nova atitude para com ela mesma e no interior da própria família.

Os homens - entre 18 a 30 anos, em geral solteiros, mas com filhos pequenos - vão aos bailes para trabalhar. Pode-se supor que como eles cruzam aquela porta para exercer uma atividade laboral e com isso, possivelmente rotineira e trivial, não há nenhum sentido em pensar numa passagem e na distinção entre "mundo anterior” e “mundo novo”. Entretanto, há sim uma passagem e símbolos que podem propiciar numa mudança de percepção individual e coletiva. Assim, aquela porta os leva para outro lugar, para o "mundo da dança"

Os dançarinos profissionais, em geral, trabalham exclusivamente nos bailes e com aulas de dança particulares e nas academias. O momento do encontro entre os dançarinos no baile é invariavelmente acalorado, eles conversam e se cumprimentam constantemente - inclusive no salão de dança onde muitas vezes param por alguns instantes de dançar para cumprimentar os colegas e apresentar as clientes -, tendo em vista que formam um grupo que compartilha certos valores pessoais e profissionais.

No tocante à relação entre clientes e dançarinos, há uma valorização do dançarino, principalmente aqueles que dançam bem, pois na dança de salão a condução é do homem, ninguém verá uma dama rodopiando lindamente no salão se não houver um cavalheiro para conduzi-la corretamente. Nas palavras da cliente: “O bom dançarino, tecnicamente falando, é aquele que tem uma condução perfeita, [faz um movimento com o tronco e os braços arqueados, postura inicial de damas e cavalheiros no salão] que me diz o quer que eu faça, esse é o exímio dançarino”. (C., advogada, administradora, auditora fiscal federal aposentada, 60 anos). É recorrente mencionarem o apreço pelo “bom dançarino”, pela "boa condução”, isso porque a visibilidade dos corpos nos bailes se dá especialmente no salão, onde os passos de dança podem ser mostrados, assim como a beleza e destreza do casal.

Outro aspecto bastante mencionado como sendo indispensável para compor um bom dançarino são os cuidados com a higiene pessoal - o banho ${ }^{9}$, a roupa lavada e

\footnotetext{
${ }^{8}$ Categoria êmica. Tanto os dançarinos quanto as clientes utilizam a expressão para se referir ao contexto da dança de salão em Fortaleza e os indivíduos que estão inseridos nele. $\mathrm{O}$ "mundo da dança" diz respeito aos bailes, às academias, às aulas de dança, ao pagamento de fichas ou contratos e aos homens e mulheres que participam dessas atividades.

${ }^{9}$ A necessidade do banho é mencionada em diversas ocasiões, especialmente com relação aos dançarinos que dão aula de dança, particular ou nas academias, e vão direto para o baile, muitas vezes apenas trocando a roupa.
} 
passada, os dentes e o hálito, as axilas, a barba, o cabelo. Em outras palavras, a limpeza ${ }^{10}$ e a "boa aparência" (Douglas, 1966). Diante da atividade física no salão ambos ficam suados. As clientes apreciam os dançarinos que também manifestam cuidados de higiene, elas reclamam e deixam de contratar os mais desatentos a essa questão. As mulheres desejam se apresentar da melhor maneira possível, preocupam-se com a construção de uma aparência agradável para o outro. Elas constantemente vão ao banheiro retocar a maquiagem e muitas usam leques e lenços para aplacar o calor e, conseqüentemente, o suor.

(...) é sempre aquele pensamento de ficar bem pra mim e pro ambiente. E também tem aquele pensamento de conhecer pessoas diferentes, paqueras, homens interessantes, me arrumo assim pra brilhar na noite e isso dá uma satisfação no ego. Ajeitar o cabelo, uma roupa diferente, o pensamento é esse de ir bonita e brilhar, de ter um brilho, de ser notada e que satisfaz o ego, né? Que é bom. Um momento de estar bem, de se achar bela. E esse 'ser notada' é durante a festa toda, a gente sempre fica com aquele ar que está sempre bela, é tanto que a gente sai pra retocar uma maquiagem, colocar um batom, pentear um cabelo, se olhar pra ver se está tudo bem, aquela preocupação de não suar, de não ficar suada, eu pelo menos do jeito que não gosto de homem suado, não gosto de ficar suada. (E., pensionista, 55 anos).

Percebo, então, a valorização do corpo também pela construção da aparência, um cuidado na forma de se apresentar para o outro, um desejo de ser admirado. Essa visibilidade também propicia uma valorização da auto-estima com relação ao corpo.

Observando a sociabilidade de mulheres mais velhas nos bailes de dança de salão é possível perceber corpos sensíveis e receptivos a novos estímulos. No aprendizado social da dança essa autonomia é desenvolvida não apenas em termos funcionais, mas em termos estéticos, emocionais e sensoriais.

Os discursos recorrentes em nosso meio social sobre o envelhecimento ativo e autônomo oferecem possibilidades para além do âmbito estritamente doméstico, constituindo-se como um espaço de individualização das mulheres nessa fase da vida, sendo vivenciado de forma "prazerosa”, “estimulante”, num lazer que se apresenta desvinculado da família e do lar.

\footnotetext{
${ }^{10}$ Para Mary Douglas (1966) a sujeira é um fato repugnante em inúmeras sociedades e, por outro lado, tem-se como importante a limpeza, a pureza e a ausência de qualquer perigo. Um aspecto fundamental em sua análise é a questão dos resíduos corporais serem símbolos de perigo e poder. O corpo humano, mais diretamente que o do animal, é matéria de simbolismo. Os seus limites podem representar as fronteiras ameaçadas ou precárias. Como o corpo tem uma estrutura complexa, as funções e as relações entre as suas diferentes partes podem servir de símbolos a outras estruturas complexas.
} 
As (re) descobertas corporais trazem sensações que possibilitam uma resignificação de ações e sentimentos vivenciados por elas nessa fase da vida, como por exemplo, a viuvez, separação conjugal, aposentadoria, depressões, entre outras. Em algumas falas, pode-se notar as mudanças de percepções sobre suas relações com o corpo, e como se vêem, a partir da experiência da dança de salão:

Com 13 anos de idade eu já comecei a dançar [...] eu já tinha todo tipo físico assim de uma pessoa adulta, ai eu comecei a ir, papai era músico e a gente ia com ele, eu aprendi a dançar muito rápido... Com 18 anos vim para Fortaleza, casei e dei uma parada [...] depois que eu fiquei viúva, uns 3 anos depois, eu voltei a dançar. (E., pensionista, 55 anos).

Eu fiz uma cirurgia do coração há 10 anos atrás [...] Minha vida mudou completamente depois da cirurgia e eu tive depressão [...] Para mim a dança funciona como terapia, alivia qualquer tipo de problema, é uma atividade físicoartística, envolve corpo e mente, é um lazer e tem as companhias... (C., advogada, administradora e auditora fiscal federal aposentada, 61 amos).

(...) faz 6 anos que eu comecei a dançar, eu comecei a dançar depois que... a referência é a saída do Ênio lá de casa, que a Lara ia fazer 8 anos. Aí eu comecei a dançar uns 5 meses depois que eu me separei, comecei a dançar e eu sempre fui apaixonada por dança, eu sempre gostei de dançar (...) (F., jornalista, 50 anos).

No exercício de analisar a sociabilidade entre homens e mulheres de grupos etários e sociais distintos nos bailes, percebo dois pontos importantes: O primeiro deles é compreender como as mulheres envelhecem em Fortaleza e como esse caminhar para a velhice traz consigo um processo mais amplo de individualização. O segundo ponto são as experiências corporais suscitadas a partir da dança de salão.

Tomando o primeiro ponto, podemos pensar que o envelhecimento tornouse um fato de interesse político e econômico, dado suas implicações para o mercado de trabalho. Como também, a sua relação com os avanços médicos e tecnológicos (medicinas alternativas, transplantes, avanços farmacológicos, cirurgias etc). A partir desse momento, é possível perceber diversas mudanças na relação doença e envelhecimento, morte e vida, até então, bastante ligadas a essa fase da vida.

A proposta de tratar o envelhecimento como um processo abre possibilidades de análise que dão conta das mudanças culturais nas formas de pensar e gerir a experiência cotidiana, as inúmeras representações sociais que perpassam essa fase da vida, e ainda, perceber que nem todos vivem essa experiência da mesma maneira (Peixoto, 2004:9).

Observa-se, então, uma determinada construção da velhice e de como envelhecer. Os velhos passam a ser responsabilizados pelo seu próprio bem-estar e as responsabilidades dizem respeito aos cuidados com a saúde (física e psíquica) e a busca 
de soluções para uma condição financeira confortável. Há um comprometimento do indivíduo com o seu próprio processo de envelhecer.

Para conseguir cumprir esta proposta surgem as atividades de lazer, os espaços de sociabilidade, os cuidados corporais, a preocupação com o sistema de previdência e a aposentadoria. Novos mercados são criados para novos compradores. E com tantos aparatos sociais disponíveis, leva-se a crer que, se a velhice não for bemsucedida foi por incapacidade do indivíduo (Barros, 2004).

Um aspecto fundamental para pensar o envelhecimento, em especial as experiências corporais vivenciadas nessa fase da vida, é o processo de individualização, próprio da modernidade, juntamente com seus discursos que enfatizam a independência e a autonomia. Para Singly (2000), estas duas dimensões, quando reunidas, promovem no indivíduo moderno o sentimento de estar livre e essa liberdade liga-se diretamente à sua vida privada. Esse duplo movimento de individualização - independência e autonomia - resulta, segundo o autor, de um longo trabalho de socialização efetuada, em geral, durante a infância e a adolescência.

A socialização das mulheres freqüentadoras dos bailes de dança de salão em Fortaleza está marcada por uma educação ligada ao modelo de mulher dona de casa que, assim como suas mães, se realiza de forma mediada através do bem-estar e sucesso do marido e dos filhos. Sua independência, e principalmente sua autonomia, não ocorre necessariamente na adolescência ou na fase adulta da vida, com a entrada no mercado de trabalho, por exemplo.

Nesse caso, a autonomia e independência que diferenciam jovens e adultos podem ser percebidas em uma fase de transição para a velhice, onde existia a independência financeira, mas não a autonomia e, consequentemente, o sentimento de “estar livre”. Este sentimento surge nessas mulheres a partir dos 50 anos de idade, em decorrência de um acontecimento - viuvez, separação, doença, aposentadoria - e uma escolha - a dança de salão.

O segundo ponto são as experiências corporais suscitadas a partir da escolha da dança de salão. Para que essas mulheres tenham escolhido os bailes de dança de salão como forma de sociabilidade existem “motivações” e “interesses” (Simmel, 2006) que dizem respeito ao aprendizado da dança e a abertura de uma experimentação sensorial. Outro aspecto é a possibilidade das mulheres mais velhas serem admiradas, dado que seus corpos tornam-se mais visíveis nos bailes. Essa exposição e visibilidade favorecem o interesse para com os cuidados corporais, a aparência, os modos de se 
vestir. Elas buscam “estar bem”, “se sentir bonita”, "brilhar”, dançar com destreza para ficar "bonito para o povo ver" e, principalmente, elas sentem prazer quando experimentam essas sensações.

O processo de envelhecimento dessas mulheres ocorre em referência à valorização de uma atividade lúdica onde “o corpo e a mente” podem ser experimentados conjuntamente. Em outras palavras, ao experimentarem as diversas sensações as quais seus corpos são submetidos nos bailes despertam sentimentos e emoções que poderiam ser considerados, de maneira restrita, de ordem fisiológica ou psicológica. E o que vemos é que a percepção e apropriação desse "universo de sentidos” apenas são possíveis para elas devido ao encontro com o outro, ao pertencimento social, ao seu modo particular de estar inserido num determinado contexto cultural.

Assim, abre-se espaço para o “tempo interior” em oposição ao "tempo exterior” (Bacelar, 2002), ou seja, duas perspectivas diferentes de se conceber o sentido do envelhecer. O "tempo exterior" tem como ponto de referência o tempo cronológico, onde o envelhecer está ligado ao desgaste físico e psíquico, ao desamparo e as perdas. O processo do envelhecimento é inegável e irreversível, porém, na perspectiva do “tempo interior” ele é marcado pela intensidade das experiências vividas, abrindo espaço para o tempo do desejo.

\section{Referências}

BACELAR, Rute. O desejo não tem idade: a sexualidade da mulher idosa. Recife: Fundação Antônio dos Santos Abranches - FASA, 2002.

BARROS, Myriam Morais Lins. Velhice na contemporaneidade. In: PEIXOTO, Clarice Ehlers (org.). Família e envelhecimento. Rio de Janeiro: Editora FGV, 2004.

DOUGLAS, Mary. Pureza e perigo. São Paulo: Perspectiva, 1966.

MAGNANI, José Guilherme Cantor. Festa no Pedaço: cultura popular e lazer na cidade. 2.ed. São Paulo: Editora Hucitec; Editora Unesp, 1998.

PEIXOTO, Clarice Ehlers (org.). Família e envelhecimento. Rio de Janeiro: Editora FGV, 2004.

SIMMEL, Georg. Questões fundamentais da sociologia: indivíduo e sociedade. Rio de Janeiro: Jorge Zahar Ed., 2006.

SINGLY, François. O nascimento do "individuo individualizado" e seus efeitos na vida conjugal e familiar. In: PEIXOTO, Clarice Ehlers et all (org.). Família $e$ individualização. Rio de Janeiro: Editora FGV, 2000.

SIQUEIRA, Monalisa Dias. “Quem convida é a mulher”: experiências femininas e subversão nos bailes de dança de salão. 118p. Fortaleza: Universidade Federal do Ceará, Mestrado em Sociologia, 2009. Dissertação - Universidade Federal do Ceará.

VAN GENNEP, Arnold. Os ritos de passagem: estudo sistemático dos ritos da porta e da soleira, da hospitalidade, da adoção, gravidez e parto, nascimento e infância, 
puberdade, iniciação, coroação, noivado, casamento, funerais, estações, etc; Tradução de Marino Ferreira. Petrópolis: Vozes, 1977. 